\title{
Laser performance and investigation of the optimal density functional and the dependence of the basis sets for (E, E)-2,5-bis (3,4-dimethoxystyryl) pyrazine (BDP) molecule
}

\author{
Mahmoud A. S. Sakr ${ }^{1,2}$. Sayed A. Abdel Gawad ${ }^{2}$. Samy A. El-Daly ${ }^{1}$ Maram T. H. Abou Kana ${ }^{3}$ El-Zeiny M. Ebeid ${ }^{1,2}$
}

Received: 22 March 2021 / Accepted: 12 August 2021 / Published online: 20 August 2021

(c) The Author(s) 2021

\begin{abstract}
This manuscript includes some photophysical parameters and some optical properties such as absorption and emission spectra of the (E, E)-2,5-bis (3,4-dimethoxystyryl) pyrazine (BDP) by applying sol-gel and copolymer matrices. The BDP molecular structure is incorporated in sol-gel matrix and copolymer of methyl methacrylate (MMA) and 2-hydroxyethyl methacrylate (HEMA). In case of sol-gel matrix, the BDP molecular structure has higher quantum yield in addition to photostability maxima. The laser behavior of this molecular structure containing sol-gel matrix is good senior compared to copolymer one via using diode laser $(450 \mathrm{~nm}$ ) as pumping laser of power $160 \mathrm{~mW}$. Also, the fluorescence profile of the BDP molecular structure is sensitized via using cadmium sulfide (CdS) quantum dots (QDs) by applying sol-gel host. The optimized structure of the BDP molecule is obtained via applying B3LYP/6-31G(d) level of theory. The electronic absorption and emission spectra of the BDP molecular structure in ethanol solvent were calculated using time-dependent density functional theory (TDDFT) at CAM-B3LYP/6-31G + + (d, p) level. The obtained theoretical results were compared to experimental ones.
\end{abstract}

Keywords Sol-gel · Copolymer · Quantum dots (QDs) · Laser behavior · Photostability · Time-dependent density function theory (TDDFT)

\section{Introduction}

In our previous work, some photophysical parameters, laser performance, quantum dot photosensitization, and TDDFT of (E, E)-2,5-bis [2-(4-(dimethylamino)phenyl) ethenyl] pyrazine (BDPEP) molecular structure via applying sol-gel and copolymer matrices are studied [1]. Consequently, the same previous studies for BDP molecular structure are investigated due to the different chemical structure of BDP molecule compared to BDPEP molecular structure.

El-Zeiny M. Ebeid

mahmoud.sakr@must.edu.eg

1 Chemistry Department, Faculty of Science, Tanta University, Tanta, Egypt

2 Misr University for Science and Technology (MUST), 6Th of October City, Egypt

3 Laser Systems Department, National Institute of Laser- Enhanced Science (NILES), Cairo University, Cairo, Egypt
As of late, a great deal of a work is presented to actualize laser dyes via applying solid-state as a useful option in contrast to the partner of liquid dye lasers owing to their compactness, ease of manufacture, low cost of fabrication, simplicity, and well-being in taking care of and activity, in addition to avoiding lack of toxicity, flammability, flow fluctuations, and solvent evaporation problems [2-4]. A lot of laser dyes via applying solid hosts have been broadly announced [5-15]. In solid-state dye lasers (SDDL) [16], the dye is interacted with matrix through hydrogen bonds among the dye and hydroxyls. This allows the dye to be adsorbed on the surface of the matrix, thereby preventing the dye bimolecular reactions and upgrading the dye thermal and environmental stability $[17,18]$.

The gain region was tailored over a wide range through the self-modulation of the optically activated ICT isomers. Meanwhile, the resonant modes shifted with the photoisomerization because of a change in the effective refractive index of the polymer microdisk cavity [19]. Polystyrene (PS) and poly (methylmethacrylate) (PMMA), with different polarities, were selected as the matrix materials to create Janus microlasers. The Janus structures were obtained by 
Scheme 1 Reaction progress of preparation of BDP molecule<smiles>COc1ccc(/C=C/c2cnc(/C=C/c3ccc(OC)c(OC)c3)cn2)cc1OC</smiles>

inducing phase separation of PS/ PMMA within the micrometer-sized emulsion droplets [20]. Laser displays, benefiting from the characteristic merits of lasers, have led to the revolution of next-generation display technologies owing to their superior color expression. However, the acquisition of pixelated laser arrays as self-emissive panels for flat-panel laser displays remains challenging. Liquid crystal (LC) materials with excellent processability and optoelectronic properties offer considerable potential for the construction of highly ordered multicolor laser arrays [21]. Miniaturized lasers with multicolor output and high spectral purity are indispensable for various ultracompact photonic devices. Here, we propose an optically reconfigurable Förster resonance energy transfer (FRET) process to realize broadband switchable single-mode lasing based on in situ activation of acceptors [22].
In a prior investigation, we detailed the laser activity and optical behavior of the BDP laser dyes in organic solvents [23]. Hence, the study the performance of this laser dye via applying sol-gel matrix and copolymer media is essential to upgrade the nature of laser action. The existence of HEMA kept up the transparency of solid matrix as well as ensured a good solubility of probe dye because of the polar character of HEMA [24, 25]. In the preparation of copolymer (MMA and HEMA), azobisisobutyronitrile (AIBN) was used as an initiator for free radical bulk polymerization of HEMA and MMA. The optical properties and lasing action of the BDP molecule via applying sol-gel and copolymer matrices are assessed.

Organic particles with huge delocalized л-electron systems along their backbone have attracted significant interest because of potential applications related with strong
Scheme 2 Preparation procedures for sol-gel matrix

\section{1-Hydrolysis:}

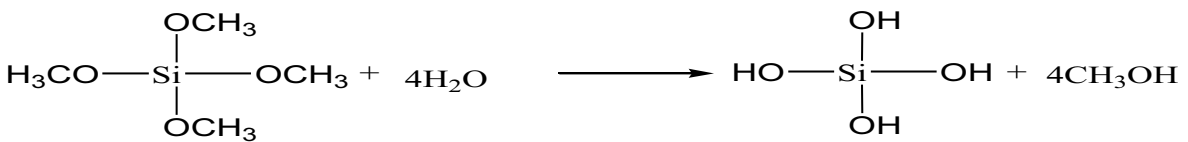

2-Condensation:

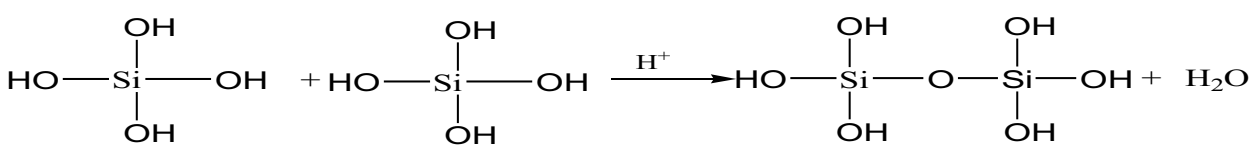

3-Further condensation:<smiles>O[Si](O)(O)O[Si](O)(O)[OH+]</smiles><smiles>O[Si](O)(O)O[Si](O[Si](O)(O)O)(O[Si](O)(O)O)O[Si](O[Si](O)(O)O)(O[Si](O)(O)O)O[Si](O)(O)O</smiles> 
Fig. 1 Normalized absorption (in black) and emission (in red) spectra of $1 \times 10^{-5} \mathrm{M}$ BDP in sol-gel and copolymer matrices

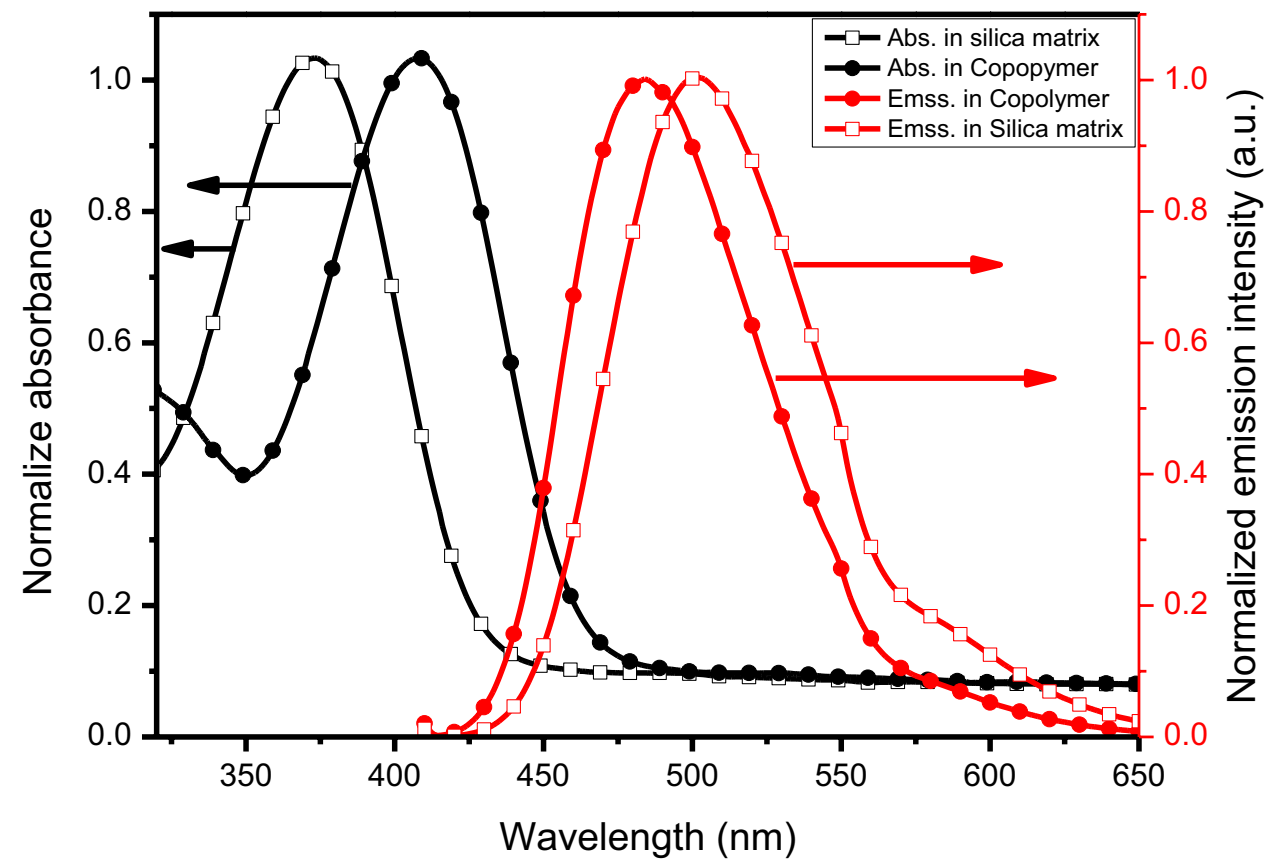

emission behavior and enormous nonlinear optical properties [26-28]. The electron-donating and electron-withdrawing groups play important roles in the optical properties of organic compounds [29]. The six-membered ring that contains nitrogen atoms at the 1,4 positions is called pyrazines [29, 30]. Having highly electron-withdrawing character, pyrazine compounds are perfect for the incorporation as electron-withdrawing groups in favoring intramolecular charge transfer (ICT) [29].

Quantum dots (QDs) have large potential uses as photosensitizers for a variety of application. Upon resizing the QDs, the electronic absorption and emission spectra of it can be adjusted. Studies recording the factors controlling the potential energy transfer process among donor molecule (QD) and acceptor molecules are investigated [31].

\section{Materials and methods}

\section{Materials preparation}

\section{The BDP molecule preparation [32]}

In dimethylformamide (DMF), the mixture from 2,5-dimethylpyrazine $(0.5 \mathrm{~g}, 0.00462 \mathrm{M})$ and 3,4-dimethoxybenzaldhyde
$(2.3 \mathrm{~g}, 0.013 \mathrm{M})$ were dissolved and the mixture were cooled to $0.0{ }^{\circ} \mathrm{C}$ (Scheme 1). Then, potassium-tert-butanolate (1.55 g, $13 \mathrm{mM}$ ) was added with small amount to this mixture and brought to ambient temperature. Via applying stirrer, the mixture was stirred till completely consumed. By extraction with chloroform, the product was isolated after the completion the reaction. The product material obtained was recrystallized to give $(1.4 \mathrm{~g}, 52 \%)$ as a yellow solid. The structure of the compound was assured via applying ${ }^{1} \mathrm{H}$ NMR and ${ }^{13} \mathrm{C}$ NMR.

\section{The preparation sol-gel matrix containing the BDP molecule [32]}

The sol-gel matrix was prepared as follows (Scheme 2): via applying the magnetic stirrer, we mix $(11.00 \mathrm{~mL}$ tetraethoxysilane (TEOS) (Aldrich, 98\%), $6.00 \mathrm{~mL}$ methanol (Aldrich), $9.00 \mathrm{~mL}$ distilled water, $1 \mathrm{~mL}$ of hydrochloric acid $(\mathrm{HCl})\left(\right.$ Merck, approximately $35 \%$ pure, $1.18 \mathrm{gm}^{-1}$ ) $(0.1 \mathrm{~N})$ as a catalyst, and $8.00 \mathrm{~mL}$ glycerol (Merck, IP for analysis) as a drying control chemical (DCCA) for $6 \mathrm{~h}$ at $60{ }^{\circ} \mathrm{C}$. In polystyrene cuvette, $1.00 \mathrm{~mL}$ of the BDP solution is mixed with $3.00 \mathrm{~mL}$ sol. It was dehydrated and aging for about 3 weeks via applying a controlled oven at $60{ }^{\circ} \mathrm{C}$.
Table 1 Photo physical parameters of BDP molecule by applying sol-gel and copolymer matrices

\begin{tabular}{lllllll}
\hline Hosts & $\lambda_{\text {abs }}(\mathrm{nm})$ & $\lambda_{\text {ems }}(\mathrm{nm})$ & $\phi_{\mathrm{f}}$ & $f$ & $\mathrm{~K}_{\mathrm{r}} \times 10^{9}\left(\mathrm{~S}^{-1}\right)$ & $\mu_{12}($ Debay $)$ \\
\hline Sol-gel & 374 & 502 & 0.52 & 0.82 & 0.85 & 9.63 \\
Copolymer & 409 & 485 & 0.43 & 0.62 & 0.79 & 8.62 \\
\hline
\end{tabular}



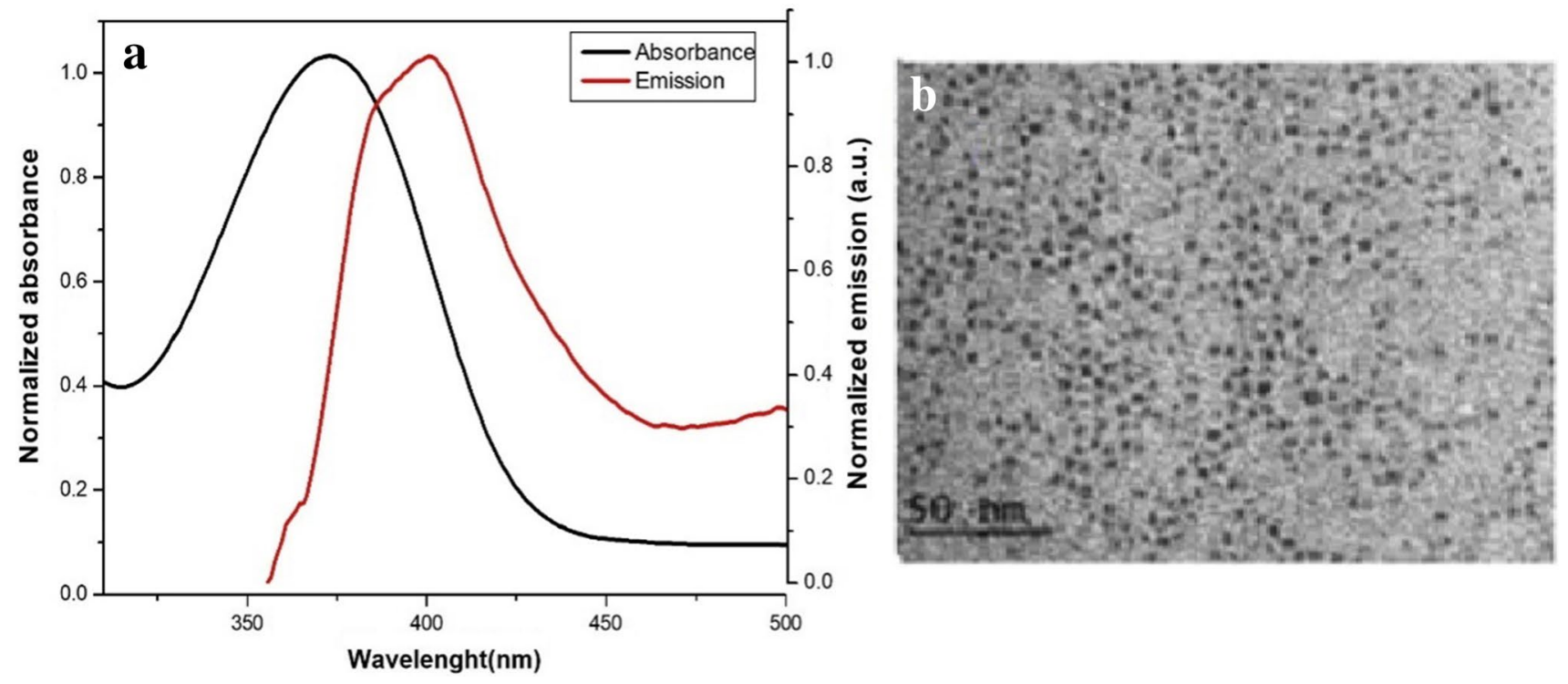

Fig. 2 a The spectral overlaps of $1 \times 10^{-5} \mathrm{M}$ of BDP absorption and $6.6 \times 10^{-6} \mathrm{~mol} / \mathrm{L} \mathrm{CdS}$ QDs emission spectra (excitation wavelength $\lambda_{\text {ex. }}=380 \mathrm{~nm}$ ) in silica matrix. b The TEM image of CdS QDs

\section{The preparation of sol-gel matrix containing CdS QDs [33]}

In order to prepare QDs in the silica matrix, QDs should be synthesized in aqueous rather than organic medium, as the solubility of aqueous QDs in sol-gel is excellent compared to organic QDs. Thus, CdS QDs in aqueous media is prepared as follows: $250 \mathrm{~mL}$ three-necked flask. In this flask, we mixed $100 \mathrm{~mL} \mathrm{CdCl}_{2}(0.02 \mathrm{M}), 2.5 \mathrm{~mL} \mathrm{H}_{2} \mathrm{O}$, then under stirring, $1.0 \mathrm{~mL}$ from thioglycolic acid was added. The $\mathrm{PH}$ was fixed to 12.00 via using $1.00 \mathrm{M} \mathrm{NaOH}$. Then, $0.3 \mathrm{~mL}$ of $30 \% \mathrm{H}_{2} \mathrm{O}_{2}$ drop wisely added in the flask after moving the solution for $10 \mathrm{~min}$.

\section{The preparation of copolymer (MMA/ HEMA) containing BDP molecule [34]}

The copolymer of methylmethacrylate (MMA) and hydroxyethyl methacrylate (HEMA) was prepared via mixing MMA and HEMA (volume ratio 2:1) monomers containing the initiator azobisisobutyronitrile (AIBN) $3 \mathrm{~g} / \mathrm{L}$ dissolved in it. Then, the prepared solution was subjected to ultrasonic stirring for about 15 min until the initiator was completely dissolved. After that, the BDP solution was added to obtain the desired concentration and allowed to dissolve in the ultrasonic bath for up to $20 \mathrm{~min}$. In controlled clean oven at $60{ }^{\circ} \mathrm{C}$ as an optimum temperature regarding physical appearance and transparency, drying and aging were carried out. After 1 week from the date of preparation, the samples got dried so they could be handled and subjected to various measurements.

\section{Characterization}

Via applying a transmission electron microscope (TEM) with acceleration voltage up to $200 \mathrm{kV}$, the morphology and the size of the CdS QDs were recorded. Utilizing UV-Vis spectrophotometer (Shimadzu UV-2450), the optical properties of the BDP molecule are measured over a range of 200-700 nm. The fluorescence properties were measured via utilizing spectrofluorometer (Shimadzu, RF-5301PC).

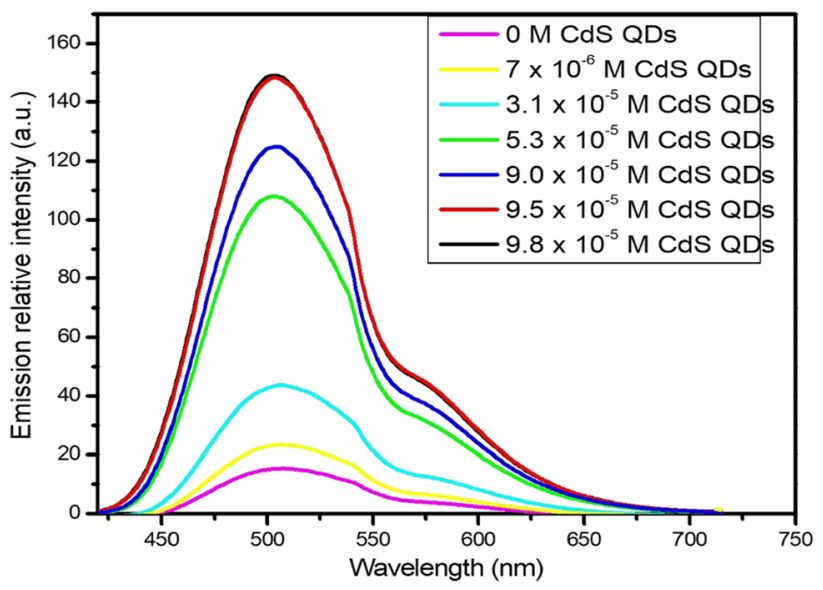

Fig. 3 Emission spectra of $1 \times 10^{-5} \mathrm{M}$ BDP dye in sol-gel matrix at different concentrations of CdS QDs (excitation wavelength $\lambda_{\text {ex. }}=380 \mathrm{~nm}$ ) 


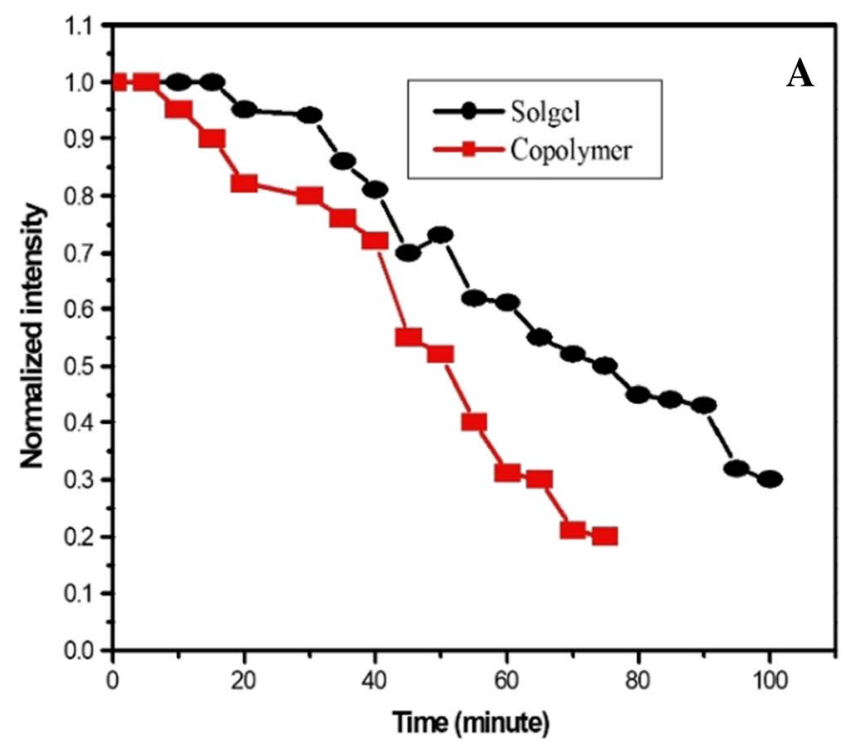

Fig. 4 The output intensity as a function of time utilizing a 450-nm wavelength diode laser and a power of $160 \mathrm{~mW}$ as a source of pumping (A) and the output intensity as a function of different input energy

\section{Results and discussion}

The electronic absorption and emission spectra of the studied molecule was measured experimentally via applying sol-gel and copolymer matrices; the results are presented in Fig. 1. The electronic absorption spectrum of the studied molecular structure in sol-gel and copolymer matrices consists of mainly one peak appearing at 374 and $409 \mathrm{~nm}$, respectively. It is assigned as $\pi-\pi^{*}$ transition as indicated by its extinction coefficient, 8280 and $7250 \mathrm{Lmol}^{-1} \mathrm{~cm}^{-1}$ for the studied molecule via applying sol-gel and copolymer matrices, respectively. On the other hand, the electronic emission spectra of the studied system were also recorded by applying sol-gel and copolymer matrices and presented in Fig. 1. The experimental maximum emission wavelength of the BDP molecular structure in sol-gel and copolymer matrices is 502 and $485 \mathrm{~nm}$, respectively. As presented in Fig. 1, the interference among the experimental electronic absorption and emission spectra were not observed by applying sol-gel

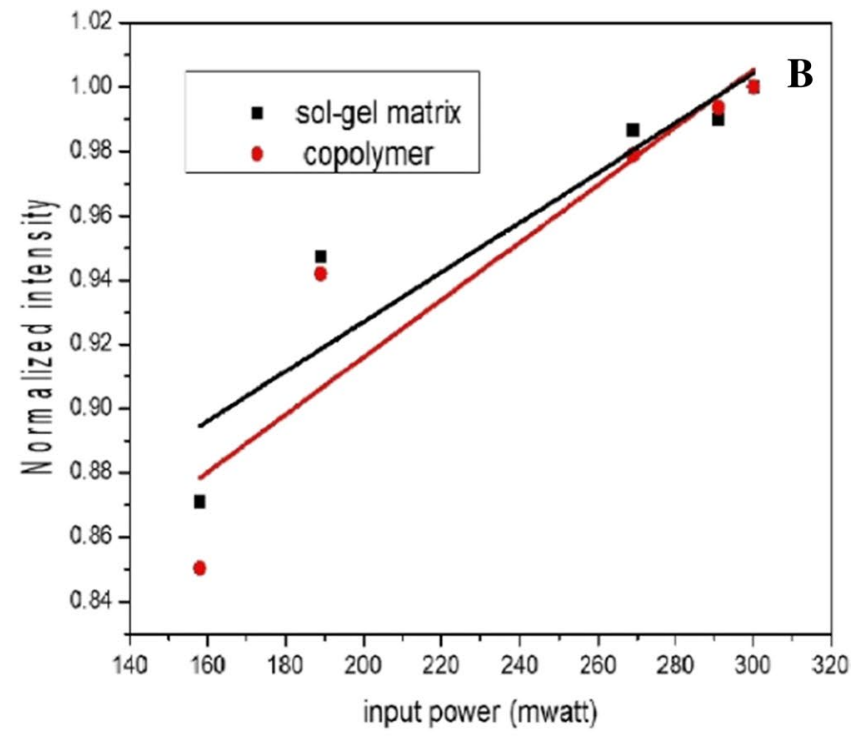

(B) for $1 \times 10^{-3} \mathrm{M}$ BDP dye by applying both sol-gel and copolymer matrices utilizing diode continuous laser $(\lambda=450 \mathrm{~nm})$

contrast to copolymer one. Therefore, the reabsorption of the experimental electronic emission photons of the studied molecular structure has not been occurred by applying sol-gel matrix contrast to copolymer host as presented in Fig. 1.

Via utilizing Fig. 1, the fluorescence quantum yield $\left(\phi_{\mathrm{f}}\right)$ $[34,35]$, oscillator strength $(f)$, transition dipole moment from ground to excited state $\left(\mu_{12}\right)[36,37]$, and radiative decay rate constant $\left(\mathrm{K}_{\mathrm{r}}\right)$ [38] for the studied molecule by applying sol-gel and copolymer matrices are estimated and presented in Table 1. The $\phi_{\mathrm{f}}$ value of the studied molecule by applying sol-gel matrix is high in contrast to copolymer matrix as listed in Table 1, owing to high mobility of the BDP molecules in sol-gel compared to copolymer host. In addition, the highest value of $\mathrm{K}_{\mathrm{r}}$ of the BDP molecule embedded sol-gel matrix in contrast to copolymer one as shown in Table 1. Referring to the high singlet-triplet splitting energies $\left(\Delta \mathrm{E}_{\mathrm{S}, \mathrm{T}}\right)$ of the studied molecular structure by applying sol-gel matrix compared to the copolymer host [39-42]. The value of $f$ and $\mu_{12}$ of the studied molecule via
Fig. 5 Optimized geom. of compound

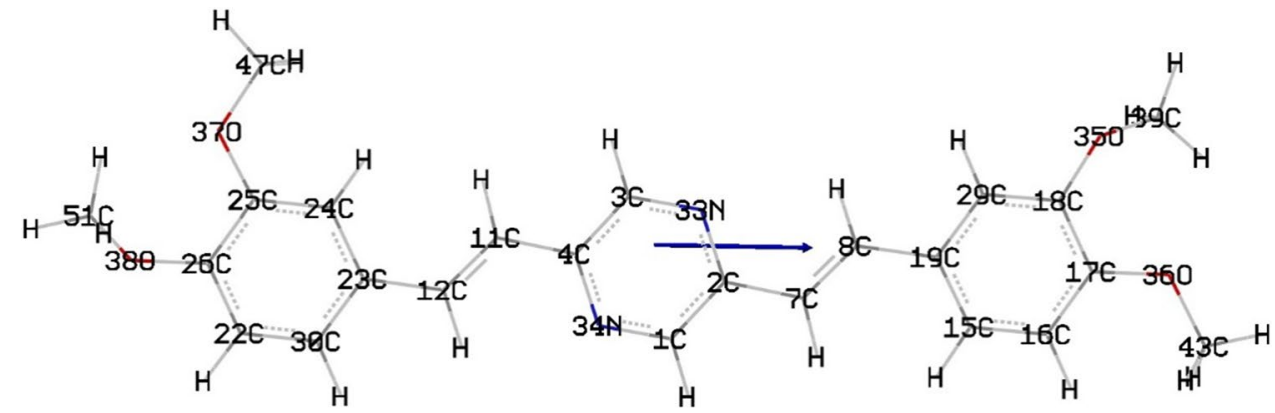


Table 2 Selected optimized geometrical parameters (bond length in $\AA$ and dihedral angle in ${ }^{\circ}$ ) computed for BDP molecule in gas phase using B3LYP/6-31G(d). For labeling, refer to Fig. 5

\begin{tabular}{llll}
\hline $\mathrm{C} 26-\mathrm{O} 38$ & 1.373 & $\mathrm{C} 47-\mathrm{O} 37-\mathrm{C} 25-\mathrm{C} 26$ & 179.77 \\
\hline $\mathrm{C} 25-\mathrm{O} 37$ & 1.363 & $\mathrm{C} 51-\mathrm{O} 38-\mathrm{C} 26-\mathrm{C} 22$ & 110.78 \\
$\mathrm{C} 23-\mathrm{C} 12$ & 1.461 & $\mathrm{C} 3-\mathrm{N} 33-\mathrm{C} 2-\mathrm{C} 7$ & 179.79 \\
$\mathrm{C} 12-\mathrm{C} 11$ & 1.351 & $\mathrm{C} 39-\mathrm{O} 35-\mathrm{C} 18-\mathrm{C} 29$ & 108.97 \\
$\mathrm{C} 11-\mathrm{C} 4$ & 1.457 & $\mathrm{C} 43-\mathrm{O} 36-\mathrm{C} 17-\mathrm{C} 18$ & 179.61 \\
$\mathrm{C} 2-\mathrm{C} 7$ & 1.456 & $\mathrm{C} 16-\mathrm{C} 17-\mathrm{O} 36$ & 124.89 \\
$\mathrm{C} 7-\mathrm{C} 8$ & 1.352 & O35-C18-C17 & 120.85 \\
$\mathrm{C} 8-\mathrm{C} 19$ & 1.459 & O37-C25-C26 & 115.69 \\
$\mathrm{C} 17-\mathrm{O} 36$ & 1.359 & O38-C26-C25 & 121.11 \\
$\mathrm{C} 18-\mathrm{O} 35$ & 1.377 & $\mathrm{C} 12-\mathrm{C} 11-\mathrm{C} 4$ & 124.11 \\
\hline
\end{tabular}

applying sol-gel and copolymer matrices indicating $\left(\mathrm{S}_{0}\right.$ to $\mathrm{S}_{1}$ electronic transition).

The experimental overlapping between electronic absorption spectrum of the studied molecule and emission spectrum the CdS QDs by applying sol-gel matrix was examined; the results are given in Fig. 2a. Via applying the following equations [43],

$$
\begin{aligned}
D= & \left(1.6122 \times 10^{-9}\right) \lambda^{4}-\left(2.6575 \times 10^{-6}\right) \lambda^{3} \\
& +\left(1.6242 \times 10^{-3}\right) \lambda^{2}-(0.4277) \lambda+(41.57) \\
\varepsilon= & 5857(D)^{2.65}
\end{aligned}
$$

where $D(\mathrm{~nm})$ is the size of the nanocrystal administration sample, $\lambda(\mathrm{nm})$ is the wavelength, and $\varepsilon$ is the molar absorptivity of the first excitonic absorption peak of the corresponding sample. The used molar concentration of the synthesized CdS QDs was $6.6 \times 10^{-6} \mathrm{M}$ and the CdS QDs size was 3-6 nm. The CdS QDs TEM image is shown in Fig. 2b.

Due to large overlapping between emission spectrum of the CdS QDs and absorption spectrum of the studied molecule by applying sol-gel matrix as presented in Fig. 2a. The emission spectrum of the studied molecule was upgraded in sol-gel matrix via adding different concentrations of CdS QDs as shown in Fig. 3. The experimental electronic maximum fluorescence intensity at $503 \mathrm{~nm}$ is enhanced subsequently and the position of the electronic maximum emission wavelength at $503 \mathrm{~nm}$ is not influenced as shown in Fig. 3.This refers to the fluorescence emission of the studied molecule in sol-gel matrix which is photosensitized via applying different concentration of CdS QDs.

Assume that the photo-stability of the sample is defined as the time needed to reduce the energy output intensity to half of its value. Hence, the half-life time of the BDP molecular structure embedded sol-gel and copolymer matrices is 70 and 50 min, respectively, as shown in Fig. 4A using a 450-nm wavelength diode laser and a power of $160 \mathrm{~mW}$ as a source of pumping. Consequently, the half-life time of the BDP molecular structure via applying sol-gel matrix is higher than that copolymer because the mobility of the BDP molecules in sol-gel matrix is higher than that in copolymer.

Suppose that the amplified spontaneous emission (ASE) efficiency is defined as the ratio between the output energy of the target molecule over arrange of input pumping energy [44]. Hence, the ASE (a.u.) efficiency of $1 \times 10^{-3} \mathrm{M}$ BDP molecule via applying sol-gel matrix is higher than that in copolymer as given in Fig. 4B, which indicates the highest number of excited BDP molecules in sol-gel matrix in contrast to copolymer one. Via utilizing diode laser of 450$\mathrm{nm}$ wavelength, the input energy was controlled and varied between 160 and $300 \mathrm{~mW}$.
Fig. 6 The graphical presentation of the highest occupied (HOMO) and lowest unoccupied molecular (LUMO) orbitals of BDP molecular structure in gas via utilizing B3LYB/6$31 \mathrm{G}(\mathrm{d})$ level of theory
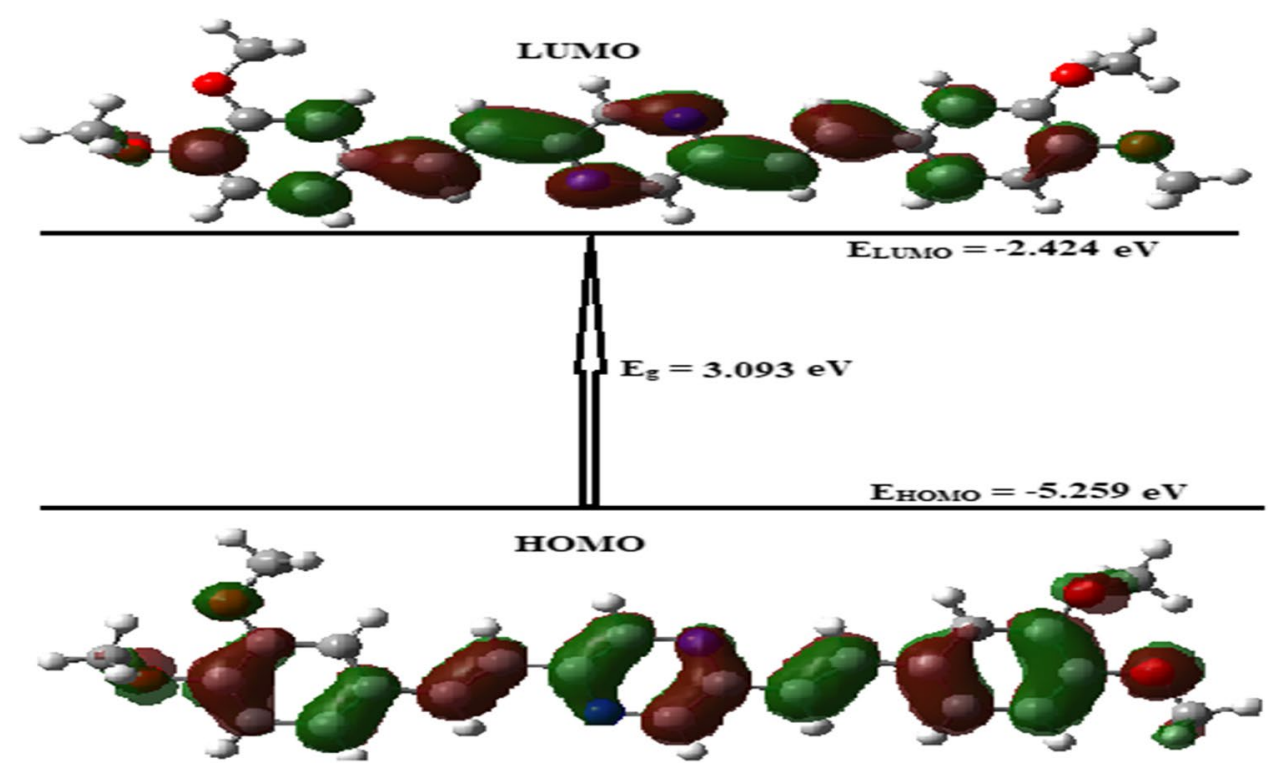


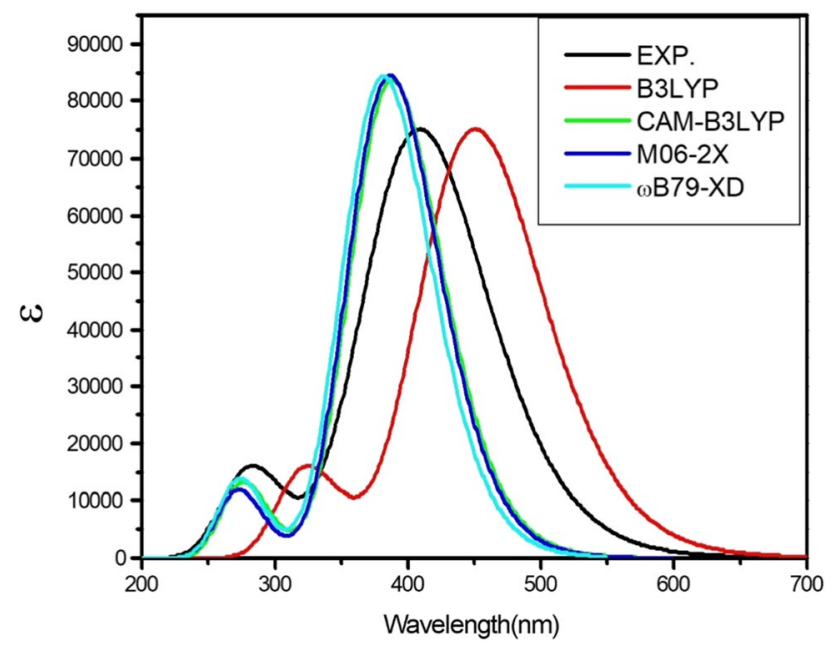

Fig. 7 Calculated absorption spectra of BDP molecular structure given with the utilization of various functionals, B3LYP, CAMB3LYP, M06-2X, and $\omega$ B97X-D and experimental absorption spectrum of the BDP (in black). Y-axis refers to calculated absorptivity. The 6-31G(d) basis set was satisfied

The electronic ground-state structures of the studied compounds were obtained utilizing the density functional theory (DFT) [45] method. The chemical structure optimizations were carried out at the [46, 47] B3LYP/6-31G(d) level of theory and the results are given in Fig. 5. BDP molecular structure planar is presented in Fig. 5. The geometrical parameters of the BDP compound in gas state are listed in Table 2. The labeling scheme is recorded in Fig. 5. Table 2 showed some selected bond lengths and dihedral angles of the studied BDP molecular structure. From Table 2, some comments can be listed: (1) referring to the listed dihedral angles, the two phenyl rings and the pyrazine ring together with the two vinyl groups all lie in the same plane. (2) The bond lengths of the two vinyl groups $\left(\mathrm{C}_{12}-\mathrm{C}_{11}\right.$ and $\left.\mathrm{C}_{8}-\mathrm{C}_{7}\right)$ are very slightly different
Table 3 The calculated maximum absorption wavelength (Calc. $\lambda_{\text {abs }}$. $(\mathrm{nm}))$ of the BDP in ethanol with the use of different basis sets and practical absorption wavelength (Exp. $\lambda_{\text {abs }}$ (nm)). The CAM-B3LYPfunctional was applied

\begin{tabular}{lll}
\hline Basis sets & Calc. $\lambda_{\text {abs }}(\mathrm{nm})$ & Pract. $\lambda_{\text {abs }}(\mathrm{nm})$ \\
\hline $6-31 \mathrm{G}(\mathrm{d})$ & 388 & 408 \\
$6-31 \mathrm{G}(\mathrm{d}, \mathrm{p})$ & 388 & \\
$6-31 \mathrm{G}+(\mathrm{d}, \mathrm{p})$ & 401 & \\
$6-31 \mathrm{G}++(\mathrm{d}, \mathrm{p})$ & 401 & \\
$6-311 \mathrm{G}$ & 382 & \\
$6-311 \mathrm{G}(\mathrm{d}, \mathrm{p})$ & 395 & \\
$6-311 \mathrm{G}++(\mathrm{d}, \mathrm{p})$ & 406 & \\
\hline
\end{tabular}

(ca. $0.001 \AA$ ). (3) The two methyl groups that bind to $\mathrm{O}_{38}$ and $\mathrm{O}_{35}$ rotate by dihedral angle 110.78 and $108.97^{\circ}$ due to steric hindrance.(4) The obtained bond angles refers to the $\mathrm{sp}^{2}$ hybridization over the entire molecular structure. (5) The changes in the obtained bond lengths as all carbon-carbon, ring's carbon-oxygen, and ring's carbon-nitrogen bonds are either doubly bonded or partially multiply bonded.

The graphical presentation of the HOMO/LUMO orbitals and energy gap between HOMO and LUMO $\left(E_{g}\right)$ for BDP compound in gas at B3LYB/6-31G(d) level of theory is shown in Fig. 6. The л-bonding orbitals and the lone pairs of electrons of the oxygen atoms of the BDP molecule are delocalized over the whole BDP molecule(see Fig. 6). In addition to, the $\Omega^{*}$ anti-bonding orbitals in the LUMO energy level (see Fig. 6) are distributed over the whole of the BDP molecular structure, while the four oxygen atoms in the BDP molecule have a small part in distribution over the whole molecule.

The optimal density functional and the dependence of the basis sets for BDP molecular structure are investigated in two steps; the results are presented in Figs. 7 and 8. In the first step, the choice of the optimal dependence of the DFT
Fig. 8 Calculated electronic absorption spectra of the BDP in ethanol with different basis sets and practical absorption spectrum (in black).Y-axis refers to calculated absorptivity. The CAM-B3LYPfunctional was applied

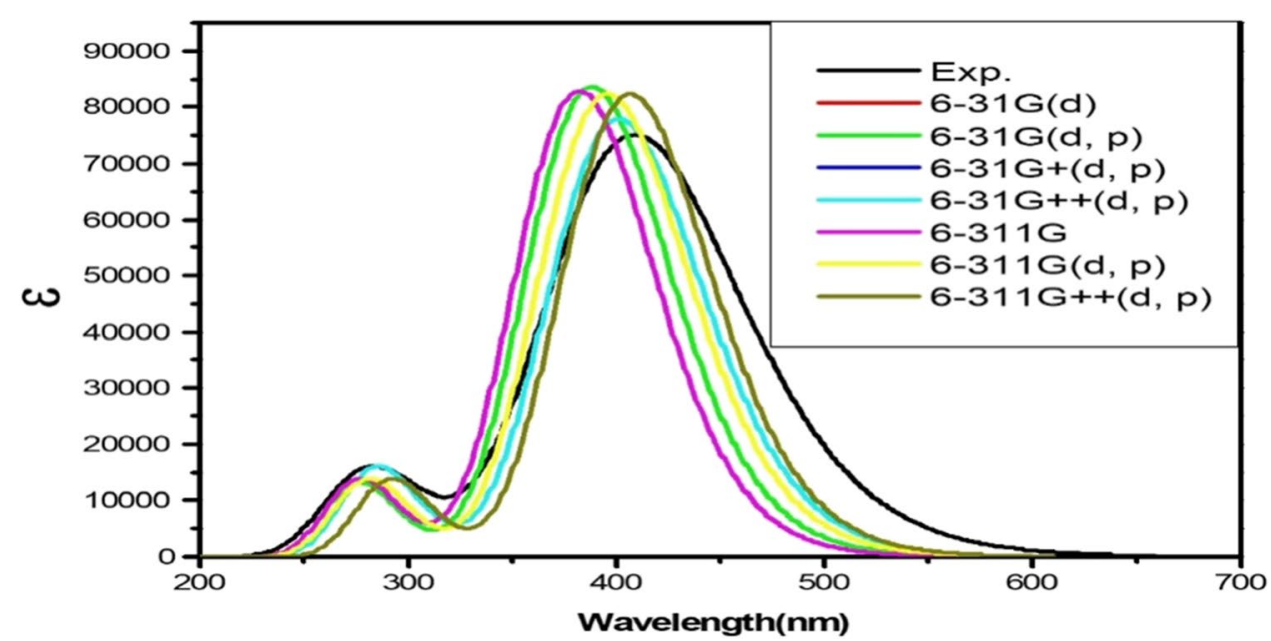




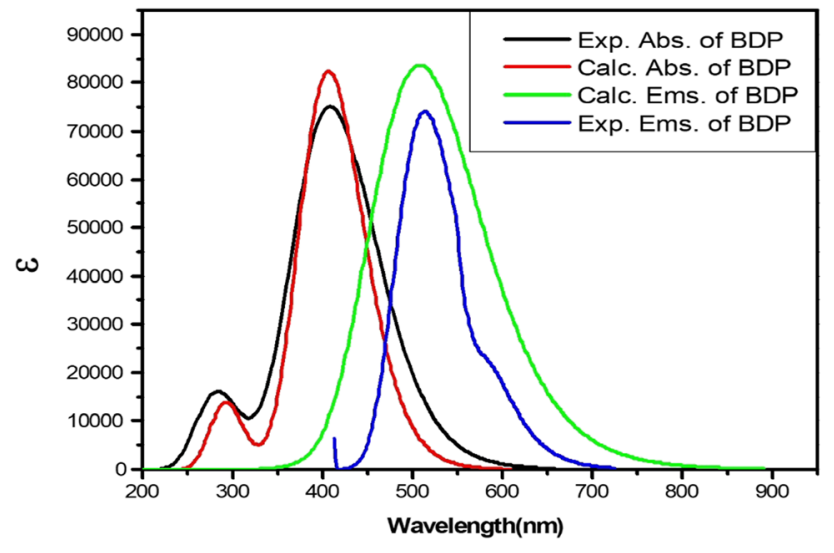

Fig. 9 Calculated electronic absorption (Calc. Abs.) and emission spectra (Calc. Ems.) of the BDP in ethanol with different basis sets and experimental absorption (Exp. Abs.) and emission spectra (Exp. Ems.) of the BDP. Y-axis refers to calculated absorptivity. The CAMB3LYP functional was applied with $6-311 \mathrm{G}++(\mathrm{d}, \mathrm{p})$ basis set

functionals are studied (B3LYP [48], CAM-B3LYP[49], M06-2X [50], $\omega B$ 97X-D [51]) [52] as recorded in Fig. 7. The optimal DFT function for calculated electronic absorption spectra of the BDP molecular structure in ethanol is CAM-B3LYP (see Fig. 7). Via applying CAM-B3LYP function, the calculated electronic absorption spectrum of the BDP molecular structure is in agreement with the experimental results as recorded in Fig. 7.

In the second step, the dependence on the basis set is recorded via applying the CAM-B3LYP functional. The computational electronic absorption spectra of the BDP molecular structure in ethanol were studied by applying different basis sets; the results are given in Fig. 8. The diffuse functions must be used to obtain the more accurate electronic absorption results for BDP molecular structure in ethanol solvent as presented in Table 3. Therefore, the optical properties of the BDP molecular structure in ethanol are investigated via applying CAM-B3LYP functional with the $6-311++\mathrm{G}(\mathrm{d}, \mathrm{p})$ basis set.

The calculated and experimental electronic absorption and emission spectra of the BDP molecule in ethanol are studied; the obtained spectra are presented in Fig. 9. The calculated electronic maximum absorption and emission wavelength of the BDP molecule are 406 and $508 \mathrm{~nm}$, respectively, as presented in Fig. 9. In addition, the experimental maximum absorption and emission wavelength of the BDP molecule are 408 and $514 \mathrm{~nm}$, respectively, as presented in Fig. 9. Therefore, the computational calculated absorption and emission spectra of the BDP molecule are in agreement with experimental results as recorded in Fig. 9. From previous study and this study, the photophysical parameters, laser performance, and QDs photosensitization of the BDPEP and BDP molecular structures are upgraded by applying sol-gel matrix compared to copolymer. In addition, the calculated optical properties of the BDPEP and BDP molecular structures are in agreement with experimental results using M062X/6-311G $++(\mathrm{d}, \mathrm{p})$ andCAM-B3LYP/6-311 + + (d, p) levels, respectively.

\section{Conclusion}

The photophysical parameters such as fluorescence quantum yield $\left(\Phi_{\mathrm{f}}\right)$, oscillator strength $(f)$, radiative decay rate constant $\left(\mathrm{K}_{\mathrm{r}}\right)$, change dipole moment from ground to excited state $\left(\mu_{12}\right)$, gain coefficient, and efficiency of the BDP molecule via applying sol-gel matrix are upgraded compared to copolymer. The mixing of CdS QDs to the BDP compound in sol-gel matrix is obtained successfully. The fluorescence emission of the BDP upon using sol-gel matrix is sensitized via adding different concentration of the CdS QDs. The lasing properties and photostability of the BDP molecule via applying sol-gel are recorded and compared to copolymer matrices. From these studies, we concluded that the photodegradation rates for the BDP molecular structure via utilizing sol-gel matrix was generally lower than via using copolymer. The optical properties of the BDP molecule are calculated using the CAM-B3LYPfunctional with the $6-311++\mathrm{G}(\mathrm{d}, \mathrm{p})$ basis set. The computational calculated absorption and emission spectra of the BDP molecule are in agreement with experimental results.

Author contribution Mahmoud A.S. Sakr: Data curation, methodology, software. Sayed A. Abdel Gawad: Software, validation. Maram T.H. Abou Kana: Visualization, investigation. Samy A. El-Daly: Supervision. El-Zeiny M. Ebeid: Writing-review and editing.

Funding This work was supported by Tanta University (Faculty of Science) and Cairo University (Laser Systems Department, National Institute of Laser- Enhanced Science (NILES).

Data availability All data generated or analyzed during this study are included in this published article.

Code availability N/A.

\section{Declarations}

Conflict of interest The authors declare no competing interests.

Open Access This article is licensed under a Creative Commons Attribution 4.0 International License, which permits use, sharing, adaptation, distribution and reproduction in any medium or format, as long as you give appropriate credit to the original author(s) and the source, provide a link to the Creative Commons licence, and indicate if changes were made. The images or other third party material in this article are included in the article's Creative Commons licence, unless indicated otherwise in a credit line to the material. If material is not included in the article's Creative Commons licence and your intended use is not permitted by statutory regulation or exceeds the permitted use, you will 
need to obtain permission directly from the copyright holder. To view a copy of this licence, visit http://creativecommons.org/licenses/by/4.0/.

\section{References}

1. Gawad SA, Eldaly S, Abou Kana M, Ebeid E-Z. (2021) Laser Performance and investigation the optimal density functional and the dependence of the basis sets for (E, E)-2, 5-bis (3, 4-dimethoxystyryl) pyrazine (BDP) molecule

2. Susdorf T, Del Agua D, Tyagi A, Penzkofer A, Garcia O, Sastre $R$ et al (2007) Photophysical characterization of pyrromethene 597 laser dye in silicon-containing organic matrices. Appl Phys B 86:537-545

3. Garcia-Moreno I, Costela A, Martin V, Pintado-Sierra M, Sastre $R$ (2009) materials for a reliable solid-state dye laser at the red spectral edge. Adv Func Mater 19:2547-2552

4. Rong-Wei F, Yu-Gang J, Yuan-Qin X, De-Ying C (2011) Enhanced laser characteristics of pyrromethene 650 using modified PMMA as solid hosts. Chin Phys B 20:84205

5. Sakr MAS, Abdel Gawad SA, Abou Kana MTH, Ebeid EZM (2017) Laser Performance of some oxazole laser dyes in restricted matrices. J Fluoresc 27:1267-1275. https://doi.org/10.1007/ s10895-017-2058-6

6. Somasundaram G, Ramalingam A (2000) Gain studies of Coumarin 490 dye-doped polymer laser. Chem Phys Lett 324:25-30

7. Russell JA, Pacheco DP, Russell WH, Aldag HR, Manenkov AA (2002) Laser threshold and efficiency measurements of solid state dye lasers operating in the near-infrared under microsecond pumping. Solid State Lasers XI, vol. 4630, International Society for Optics and Photonics; p. 24-33

8. Howell BF, Kuzyk MG (2002) Amplified spontaneous emission and recoverable photodegradation in polymer doped with Disperse Orange 11. JOSA B 19:1790-1793

9. Bergmann A, Holzer W, Stark R, Gratz H, Penzkofer A, AmatGuerri F et al (2001) Photophysical characterization of pyrromethene dyes in solid matrices of acrylic copolymers. Chem Phys 271:201-213

10. Giffin SM, McKinnie IT, Wadsworth WJ, Woolhouse AD, Smith GJ, Haskell TG (1999) Solid state dye lasers based on 2-hydroxyethyl methacrylate and methyl methacrylate co-polymers. Optics Communications 161:163-170

11. Ahmad M, King TA, Ko D-K, Cha BH, Lee J (2002) Photostability of lasers based on pyrromethene 567 in liquid and solid-state host media. Optics Communications 203:327-334

12. Costela A, García-Moreno I, Gómez C, Amat-Guerri F, Liras M, Sastre R (2003) Efficient and highly photostable solid-state dye lasers based on modified dipyrromethene BF 2 complexes incorporated into solid matrices of poly (methyl methacrylate). Applied Physics B 76:365-9

13. Costela A, García-Moreno I, Del Agua D, García O, Sastre R (2007) Highly photostable solid-state dye lasers based on siliconmodified organic matrices. J Appl Phys 101:73110

14. Zhi H, Zhi-Yu W, Yu Y, Jun C, Min-Quan W, Cheng-Fang B et al (2001) Tunable solid-state dye laser with narrow linewidth operation. Chin Phys Lett 18:225

15. Yokoyama S, Nakahama T, Mashiko S (2005) Amplified spontaneous emission and laser emission from a high optical-gain medium of dye-doped dendrimer. J Lumin 111:285-290

16. Avnir D, Kaufman VR, Reisfeld R. Organic fluorescent dyes trapped in silica and silica-titania thin films by the sol-gel method.
Photophysical, film and cage properties. Journal of Non-Crystalline Solids 1985;74:395-406.

17. Costa TMH, Stefani V, Gallas MR, Balzaretti NM, da Jornada JAH (2001) Fluorescence properties of benzoxazole type dyes entrapped in a silica matrix by the sol-gel method. J Mater Chem 11:3377-3381

18. Sakr MAS, Abdel Gawad ESA, Abou Kana MTH, Ebeid EZM (2015) Photophysical, photochemical and laser behavior of some diolefinic laser dyes in sol-gel and methyl methacrylate/2-hydroxyethyl methacrylate copolymer matrices. Opt Laser Technol 71:78-84. https://doi.org/10.1016/j.optlastec.2015.02.008

19. Qiao C, Zhang C, Zhou Z, Dong H, Du Y, Yao J et al (2020) A photoisomerization-activated intramolecular charge-transfer process for broadband-tunable single-mode microlasers. Angew Chem Int Ed 59:15992-15996

20. Wei C, Du Y, Liu Y, Lin X, Zhang C, Yao J et al (2019) Organic Janus microspheres: a general approach to all-color dual-wavelength microlasers. J Am Chem Soc 141:5116-5120

21. Xu FF, Li YJ, Lv Y, Dong H, Lin X, Wang K et al (2020) Flatpanel laser displays based on liquid crystal microlaser arrays. CCS Chemistry 2:369-375

22. Qiao C, Zhang C, Zhou Z, Yao J, Zhao YS (2021) An optically reconfigurable Förster resonance energy transfer process for broadband switchable organic single-mode microlasers. CCS Chemistry 624-32.

23. El-Daly SA, Alamry KA (2016) Spectroscopic Investigation and Photophysics of a D- $\pi$-A- $\pi$-D Type Styryl Pyrazine Derivative. J Fluoresc 26:163-176. https://doi.org/10.1007/s10895-015-1698-7

24. Costela A, Garcia-Moreno I, Figuera JM, Amat-Guerri F, Sastre R (1998) Polymeric matrices for lasing dyes: recent developments. Laser Chem 18:63-84

25. Schafer FP. Dye lasers 1990.

26. Kim HN, Guo Z, Zhu W, Yoon J, Tian H (2011) Recent progress on polymer-based fluorescent and colorimetric chemosensors. Chem Soc Rev 40:79-93

27. He GS, Tan L-S, Zheng Q, Prasad PN (2008) Multiphoton absorbing materials: molecular designs, characterizations, and applications. Chem Rev 108:1245-1330

28. Li Z, Li Q, Qin J (2011) Some new design strategies for secondorder nonlinear optical polymers and dendrimers. Polym Chem 2:2723-2740

29. Achelle S, Baudequin C, Plé N (2013) Luminescent materials incorporating pyrazine or quinoxaline moieties. Dyes Pigm 98:575-600

30. Orešić M, Danilovski A, Dumić M, Košutić-Hulita N (2001) One pot synthesis of 6, 12-dihydro-1, 3, 7, 9-tetramethyl-5H, 11H-dipyrido [1, 2-a: 1', 2'-d] pyrazine-2, 8-dione by hilbert-johnson reaction of 2-chloromethyl-3, 5-dimethyl-4-methoxypyridine. J Heterocycl Chem 38:785-790

31. Talapin DV, Rogach AL, Mekis I, Haubold S, Kornowski A, Haase $M$ et al (2002) Synthesis and surface modification of aminostabilized CdSe, CdTe and InP nanocrystals. Colloids Surf, A 202:145-154

32. Asiri AM, Alamry KA, Pannipara M, Al-Sehemi AG, El-Daly SA (2015) Spectroscopic investigation, photophysical parameters and DFT calculations of 4, 4'-(1E, 1' E)-2, 2'-(pyrazine-2, 5-diyl) bis (ethene-2, 1-diyl) bis (N, N-dimethylaniline)(PENDA) in different solvents. Spectrochim Acta Part A Mol Biomol Spectrosc 149:722-730

33. Yu WW, Qu L, Guo W, Peng X (2003) Experimental determination of the extinction coefficient of CdTe, CdSe, and CdS nanocrystals. Chem Mater 15:2854-2860

34. Macret M, Hild G (1982) Hydroxyalkyl methacrylates: hydrogel formation based on the radical copolymerization of 
2-hydroxyethylmethacrylate and 2, 3-dihydroxypropylmethacrylate. Polymer 23:748-753

35. Turki H, Abid S, El Gharbi R, Fery-Forgues S (2006) Optical properties of new fluorescent iminocoumarins Part 2 Solvatochromic study and comparison with the corresponding coumarin. Comptes Rendus Chimie 9:1252-9

36. El-Daly SA, El-Azim SA, Elmekawey FM, Elbaradei BY, Shama SA, Asiri AM (2012) Photophysical parameters, excitation energy transfer, and photoreactivity of 1, 4-bis (5-phenyl-2-oxazolyl) benzene (POPOP) laser dye. International Journal of Photoenergy 2012

37. Katchalski-Katzir E, Haas E, Steinberg IZ (1981) Study of conformation and intramolecular motility of polypeptides in solution by a novel fluorescence method. Ann N Y Acad Sci 366:44-61

38. Fahmy HM, Kandel HM, Al-Shamiri HAS, Negm NA, Elwahy AHM, Abou Kana MTH (2018) Spectroscopic Study of Solvent Polarity on the Optical and Photo-Physical Properties of Novel 9, 10-bis (coumarinyl) anthracene. J Fluoresc 28:1421-1430

39. Ebeid E-ZM, AlHazny SM (2006) Photophysical and Laser-based Techniques in Chemistry, Biology and Medicine. Booksurge

40. Bojinov V, Grabchev I (2004) Synthesis and photophysical investigations of novel combined benzo [de] anthracen-7-one/2, 2, 6, 6-tetramethylpiperidines as fluorescent stabilisers for polymer materials. Polym Degrad Stab 85:789-797

41. Yang Y, Wang M, Qian G, Wang Z, Fan X (2004) Laser properties and photostabilities of laser dyes doped in ORMOSILs. Opt Mater 24:621-628

42. Mula S, Ray AK, Banerjee M, Chaudhuri T, Dasgupta K, Chattopadhyay S (2008) Design and development of a new pyrromethene dye with improved photostability and lasing efficiency: theoretical rationalization of photophysical and photochemical properties. J Org Chem 73:2146-2154

43. Murillo AG, Calderon VHC, Romo F de JC, Velázquez DYM (2019) F-127-Assisted Sol-Gel Synthesis of Gd2O3: Eu3+ Powders and Films. Materials Research 22
44. Xu H (2017) Nanophotonics: manipulating light with plasmons. CRC Press

45. Frisch M, Trucks GW, Schlegel HB, Scuseria GE, Robb MA, Cheeseman JR, et al (2009) gaussian 09, Revision d. 01, Gaussian. Inc, Wallingford CT;201

46. Miehlich B, Savin A, Stoll H, Preuss H (1989) Results obtained with the correlation energy density functionals of Becke and Lee. Yang and Parr Chemical Physics Letters 157:200-206

47. Sun J, Li G, Liang W (2015) How does the plasmonic enhancement of molecular absorption depend on the energy gap between molecular excitation and plasmon modes: a mixed TDDFT/FDTD investigation. Phys Chem Chem Phys 17:16835-16845

48. Becke AD (1993) Becke's three parameter hybrid method using the LYP correlation functional. J Chem Phys 98:5648-5652

49. Yanai T, Tew DP, Handy NC (2004) A new hybrid exchange-correlation functional using the Coulomb-attenuating method (CAMB3LYP). Chem Phys Lett 393:51-57

50. Zhao Y, Truhlar DG (2008) The M06 suite of density functionals for main group thermochemistry, thermochemical kinetics, noncovalent interactions, excited states, and transition elements: two new functionals and systematic testing of four M06-class functionals and 12 other function. Theoret Chem Acc 120:215-241

51. Chai J-D, Head-Gordon M (2008) Long-range corrected hybrid density functionals with damped atom-atom dispersion corrections. Phys Chem Chem Phys 10:6615-6620

52. Deshpande AV, Kumar U (2002) Effect of method of preparation on photophysical properties of Rh-B impregnated sol-gel hosts. J Non-Cryst Solids 306:149-159

Publisher's note Springer Nature remains neutral with regard to jurisdictional claims in published maps and institutional affiliations. 